\title{
Maternal and Child Health Study
}

National Cancer Institute

\section{Source}

National Cancer Institute. Maternal and Child Health Study. NCI Thesaurus. Code C15812.

Studies focusing on the involvement of maternal factors (and efforts to modify these factors) that may affect the health of the child or fetus: smoking or exposure to drugs or toxic chemicals during pregnancy, maternal/fetal immunologic interactions. 